\title{
A walk through the City of Edmonton
}

Vienna Chen ${ }^{1}$, Wanda Goulden ${ }^{1}$, Joy Tolsma ${ }^{1}$, Christina Tatarniuk ${ }^{1}$, Kenzie Vie ${ }^{1}$, Kristi Olson ${ }^{1}$, Cherie Fuchs ${ }^{1}$, Kristen Kavich ${ }^{1}$

Integrated Infrastructure and Engineering Services, City of Edmonton

\begin{abstract}
As an industry placement through the WISEST Summer Research Program, an opportunity was provided to work with the City of Edmonton in an exploration of careers in engineering and architecture. The focus and scope of this placement was mainly centred around the Integrated Infrastructure and Engineering Services at the City. Through shadowing multidisciplinary engineers, technologists and architects, experience in both administrative and more hands-on work was gained. Some career pathways that were explored include materials engineering, geotechnical engineering, facilities (structural, mechanical and electrical) engineering, environmental engineering, geomatics engineering, and architecture. Throughout the duration of the program, information about the different roles and their collaboration with each other was gathered. Instead of performing research in labs, absorption of information was conducted mainly through means of observation. The City of Edmonton provided opportunities to attend various site visits, building and lab tours, and even to meetings in downtown. Tasks such as reviewing reports and drawings, attending meetings, and sitting in on business calls, all demonstrated the administrative nature of engineering and architecture. On the other hand, the more hands-on aspects of engineering were also emphasised through tasks such as assisting with field work, on-site testing, sample collecting, and data logging. With Integrated Infrastructure Services (IIS), the collaborative and interconnected nature of these careers were displayed, as each branch worked in conjunction with each other. The role of each different type of engineering and architecture is further defined in sequential order of the stages that leads to the life cycle of a construction project. This shows the direct results of each career field in contributing to the development, progression and completion of a project.
\end{abstract}

Key words:

Geotechnical Engineering, Geomatics Engineering, Construction, Surveying, Structural Engineering, Materials Engineering, Electrical Engineering, Mechanical Engineering, Environmental Engineering, Civil Engineering, City of Edmonton, Infrastructure, Architecture, Integrated Infrastructure Services, Facilities Engineering

Cite as: Chen V., Goulden W., Tolsma J., Tatarniuk C., Vie K., Olson K., Fuchs C., and Kavich K. 2019. A walk through the city of Edmonton. Alberta Academic Review, Vol 2 (2) 21-22, WISEST Special Issue (non peer-reviewed), DOI 10.29173/aar56. 
Chen et al., 2019

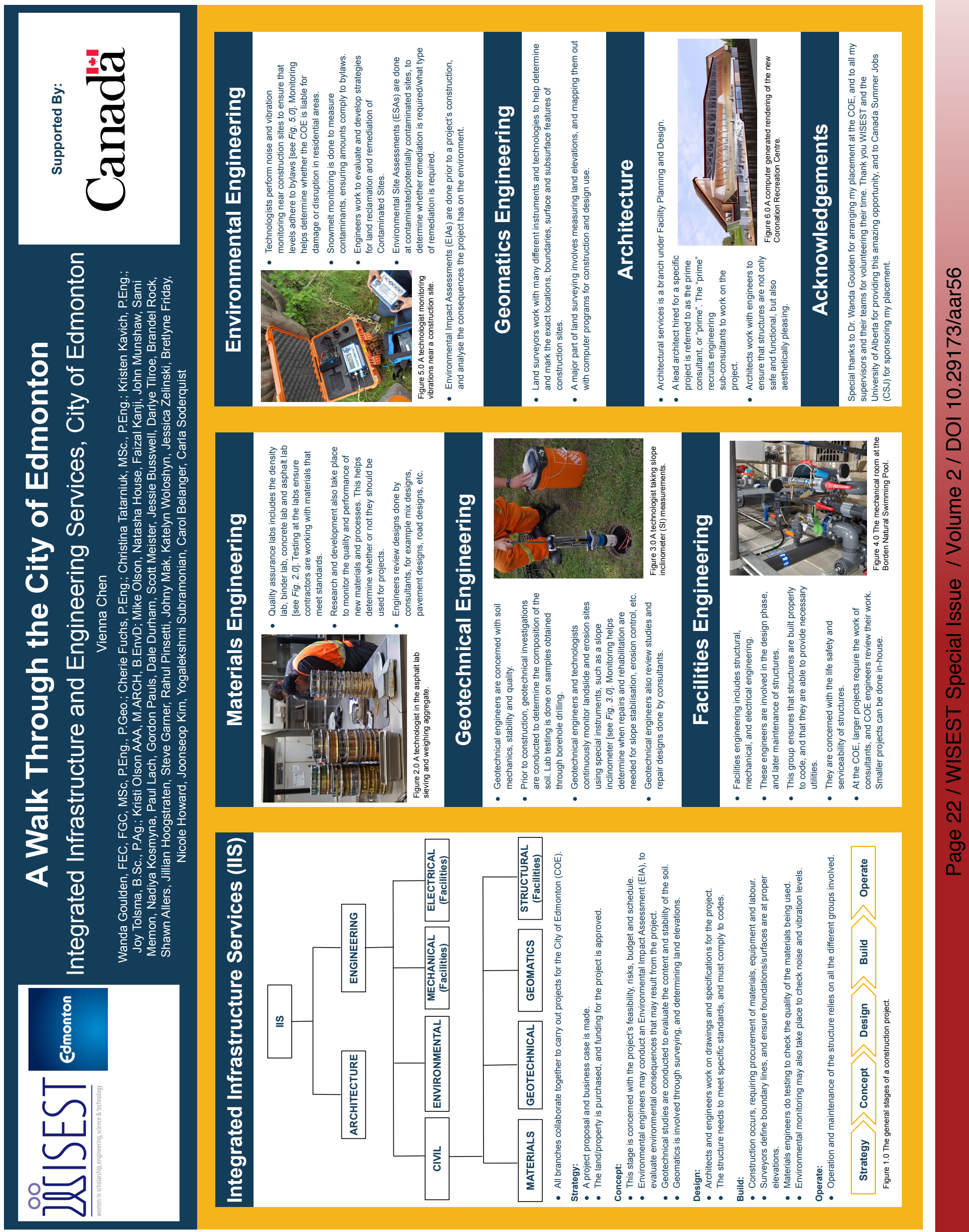

